This item was submitted to Loughborough's Research Repository by the author.

Items in Figshare are protected by copyright, with all rights reserved, unless otherwise indicated.

\title{
Facilitation of creative performance by using blue and red accent lighting in work and learning areas
}

PLEASE CITE THE PUBLISHED VERSION

https://doi.org/10.1080/00140139.2017.1349940

\section{PUBLISHER}

(C) Informa UK Limited, trading as Taylor \& Francis group

\section{VERSION}

AM (Accepted Manuscript)

\section{PUBLISHER STATEMENT}

This work is made available according to the conditions of the Creative Commons Attribution-NonCommercialNoDerivatives 4.0 International (CC BY-NC-ND 4.0) licence. Full details of this licence are available at: https://creativecommons.org/licenses/by-nc-nd/4.0/

\section{LICENCE}

CC BY-NC-ND 4.0

\section{REPOSITORY RECORD}

Kombeiz, Olga, and Anna Steidle. 2019. "Facilitation of Creative Performance by Using Blue and Red Accent Lighting in Work and Learning Areas". figshare. https://hdl.handle.net/2134/37587. 


\title{
Facilitation of creative performance by using blue and red accent lighting in work and learning areas
}

\author{
Olga Kombeiz ${ }^{1}$ and Anna Steidle ${ }^{2}$ \\ ${ }^{1}$ Olga Kombeiz \\ University of Hohenheim \\ Business and Organisational Psychology \\ Wollgrasweg 49 \\ 70599 Stuttgart, Germany \\ Email: olga.kombeiz@uni-hohenheim.de \\ ${ }^{2}$ Anna Steidle \\ Ludwigsburg University of Applied Sciences \\ Reuteallee 46 \\ 71634 Ludwigsburg, Germany
}

Manuscript accepted for publication in

Ergonomics - June 2017

The manuscript may not exactly replicate the final version published in the journal. It is not the copy of record. The final article will be available, upon publication, via its DOI:

Kombeiz, O. \& Steidle, A. (2017). Facilitation of creative performance by using blue and red accent lighting in work and learning areas. Ergonomics 61 (3), 456463. https://dx.doi.org/10.1080/00140139.2017.1349940

Acknowledgements

This paper is based on research conducted by the first author in partial fulfilment of the requirements for a doctoral degree from the University of Hohenheim and supervised by the second author. The research was funded by the Gips-Schüle Stiftung (www.gips-schuele-stiftung.de) within the graduate program People Inside (www.people-inside.de). The authors would like to express their gratitude to Jan de Boer for his helpful comments and Konrad Senf for proofreading this paper. We also thank our students for their help in collecting the data. 


\title{
Facilitation of creative performance by using blue and red accent lighting in work and learning areas
}

\author{
Research has shown that colours influence motivation and cognitive \\ performance. In achievement contexts, red evokes avoidance motivation that \\ hinders creativity, while blue elicits an approach motivation that facilitates \\ creativity. However, due to their position and mode of presentation, colours \\ may convey a different message. Red accent lighting creates a cosy, friendly \\ room atmosphere that may, even in an achievement context, elicit an \\ approach rather than an avoidance motivation. Results $(\mathrm{N}=146)$ showed \\ that both blue and red accent light increased strategic approach motivation \\ compared to white accent light. Moreover, through the heightened approach \\ motivation, colourful accent light indirectly improved creative performance. \\ Implications for future research on colour and practical implications for \\ colour usage are discussed.
}

Practitioner Summary: Designing work environments for creativity is a new topic in ergonomics research and practice. The present study demonstrates indirect effects of coloured accent light on creativity providing interesting possibilities for the design of work places for knowledge workers, classrooms, and all other rooms in which people work on new ideas.

Keywords: coloured light, accent light, colour in context, creativity, approach motivation 


\section{Introduction}

In the competitive business environment, the success of organisations depends largely on creative employees who generate potential useful ideas for product or process innovation (Dul and Ceylan 2010). Up to date, creativity has been shown to relate to some personality characteristics (e.g. openness for experience, McCrae 1987) that determines the recruitment of individuals for creative work (Scott et al. 2004). However, formal structures, time constraints and standardized work environments of traditional organisations may result in less new and useful ideas than in an innovative environment (Dul and Ceylan 2010). Thus, creativity supportive workplace could foster individual's creative performance and organisational productivity (Amabile 1996).

To find optimal environmental conditions for promoting creativity, it is important to understand how environmental features affect creative performance. It is widely acknowledged that context stimuli, like colours, can indicate safety and positive outcomes, or potential threats and negative outcomes, which in turn elicits either a creativity-supportive approach or a creativity-hindering avoidance motivation (Friedman and Förster 2010; Elliot and Maier 2012). Indeed, colours have been shown to trigger different motivational orientations (Elliot et al. 2007) and to impact creative performance (e.g., Mehta and Zhu 2009). Despite these promising findings, the idea of creativity-supportive colours has up till now not been transferred to the lighting domain. Nevertheless, coloured light for creativity promises to be a fruitful endeavour for theoretical reasons - both light (Steidle and Werth 2013) and colours (Mehta and Zhu 2009) can foster creativity - and for practical reasons - the development of creativity-supportive systems is a very hot topic these days (e.g., Siemon and Bissantz 2016). Hence, building on the framework of the colour-in-context theory (Elliot and Maier 2012), the present 
research explores the idea that coloured light activates approach (versus avoidance) motivation and indirectly promotes colourful visions (i.e., creative ideas).

\section{Colours and approach motivation}

Approach and avoidance motivation stem from distinct survival needs and relate to different desired end states. Whereas approach motivation originates from a desire for the achievement of positive outcomes, avoidance motivation stems from a need for security (Baas, De Dreu, and Nijstad 2008). Thus, approach motivation describes the direction of behaviour towards positive stimuli (i.e., events, objects, possibilities), whereas avoidance motivation describes the direction of behaviour away from negative stimuli. Elliot (2006) assumes different aspects of the definition of approach-avoidance motivation. First, the basis of the approachavoidance distinction is the concept of psychological (or physical) movement. Positively (versus negatively) evaluated stimuli are associated with motivation to keep the stimuli close to the organism (versus keeping it away, Arnold 1960). Second, approach motivation includes promoting new positive situations as well as maintaining existing positive situations, whereas avoidance motivation encompasses preventing new negative situations and escaping from existing negative situations. Third, the distinction of approach and avoidance is fundamental to motivational states, such that the absence of approach motivation does not directly mean the presence of avoidance motivation.

Such motivational states may be evoked by colours of the environment, as they convey specific positive (associated with approach motivation) or negative (associated with avoidance motivation) meanings (colour-in-context theory; Elliot and Maier 2012). Previous research on colour-associations suggests that red is related to avoidance motivation because of a "danger" signal stemming from associations with red ink in school assessments or red traffic lights (Elliot et al. 
2007; Maier, Elliot, and Lichtenfeld 2008). In contrast blue is related to approach motivation (Elliot and Maier 2012; Mehta and Zhu 2009) because of its association with tranquillity and openness (Kaya and Epps 2004). However, the colour-priming effects on avoidance and approach motivation (Mehta and Zhu 2012) were not replicated by Steele (2014). Nevertheless, according to the colour-in-context theory, the context can change a colour's meaning and consequences because the context determines which colour associations are activated. Hence, depending on the activated meaning, red may activate approach rather than avoidance motivation (Meier et al. 2012). For instance, in dating situations, red conveys a romantic meaning that is related to approach (Elliot and Niesta 2008). Moreover, in even achievement contexts, red may evoke approach motivation if the situation is framed as appetitive (potential success) rather than threatening (potential failure; Rook 2014).

\section{Colours and creativity}

Creativity is generally conceived of as the production of novel, original, and potentially useful products or ideas (Mumford 2003; Sternberg 2006). Such insights or products emerge when an individual pursues unknown or out-of-favour ideas that have growth potential (Sternberg 2006) and in situations free of threats and external pressure, thus facilitating creative thinking in the form of exploration and divergent thinking (Amabile 1983; Sternberg 1988, 1999, 2006).

Several studies indicate that the use of specific colours can increase creativity (Dul and Ceylan 2010; Lichtenfeld et al. 2012; Mehta and Zhu 2009). Accordingly, Mehta and Zhu (2009) showed that a blue computer display improves creative performance compared to a red or a neutral screen. Other research investigated wall colours that give the colours a decorative value rather than signalling success or failure and found no differences in creative performance between employees in 
offices with blue vs. red walls (Küller, Mikellides, and Janssens 2009). These partly inconsistent findings imply the importance of investigating underlying processes that may stem from different colour meanings in different contexts.

\section{Approach motivation and creativity}

The research on the link between motivational states and creativity assumes that intrinsic task-focused motivation is essential to creativity (Amabile 1983). Such motivational states are not inherent in a person, are subjective, and thus may have positive or negative connotations (Sternberg 2006). Approach motivational states originate from positively evaluated stimuli, engender restructuring of problem information, and promote access to cognitive material that is usually not or less accessible (Martindale 1995; Mednick 1962; Smith and Blankenship 1991). Such an expanded and global attentional scope facilitates creative performance. In contrast, avoidance motivation engenders a narrow attentional scope and a focus on perceptual details that is detrimental for creativity (Derryberry and Tucker 1994). In their meta-analysis, Baas, De Dreu, and Nijstad (2008) supported the idea that creativity is enhanced by approach motivation rather than avoidance motivation. In line with the colour-in-context theory, approach and avoidance motivation have been proposed and investigated as underlying processes of the colour-creativity effect (Elliot and Maier 2012; Mehta and Zhu 2009). In most laboratory studies, colours were displayed at a work-related location (e.g., on a computer display or a work folder), activating an achievement context in which red (blue) should trigger an avoidance (approach) motivation. Thus, one study showed improved creativity due to the approach motivation evoked by the colour blue (Mehta and Zhu 2009). However, when red signalled potential success rather than potential failure in an achievement situation, seeing a red folder led to more creativity than seeing a blue or white folder (Rook 2014). These findings suggest that creativity may depend on 
colour meanings and the associated motivation to a greater degree than on the colour itself.

\section{Meaning of coloured light as part of the room design}

Although light and colour are closely related - light shapes colour perception (Boyce 2014) and both have been used for room design - colour and lighting research has typically been performed separately. In recognition of this state of affairs, only recently researchers (e.g. Elliot 2015) pointed out that the role of light should be considered in colour research. To understand which light colours may evoke a creativity-supportive approach motivation, it is important to consider how coloured light is perceived and which atmosphere and feelings it evokes. These perceptions indicate the underlying visual messages associated with a specific coloured light and may evoke approach or avoidance motivation. Previously, coloured light served primarily decorative purposes and has been used as accent light to create specific atmospheres. While cold coloured accent lighting (e.g., blue, cyan) contributes to a lively and activating ambience, warm coloured accent light (e.g., red, orange) contributes to a cosy and relaxing ambience (Kuijsters et al. 2015). Both lively and cosy rooms provide a pleasant atmosphere that may foster approach motivation.

Moreover, coloured accent lighting directed at a wall may create a similar impression as a coloured wall. Several studies indicate that blue and green walls elicit more pleasant feelings than red or orange (Dijkstra, Pieterse, and Pruyn 2008; Kwallek et al. 1997), while other studies found opposing results, recording more pleasant feelings in red than in blue rooms (Küller, Mikellides, and Janssens 2009), or no effects at all (Bakker 2013). Importantly, Küller and colleagues (2009) also reported more positive feelings among employees in colourful than in neutral or colourless offices. This again hints at the possibility that both red and blue accent 
light directed at a wall may create a positive ambience that triggers approach motivation.

Building on previous research that shows that blue and red accent lighting and wall colours may create a more pleasant ambience than their colourless counterparts, we expected that blue and red coloured accent light would lead to a stronger approach motivation than white accent light (Hypothesis 1). Moreover, due to the link between approach motivation and creativity (Mehta and Zhu 2012; Rook 2014; Smith, Ward, and Finke 1995), we proposed that the heightened approach motivation in the coloured accent lighting conditions would also indirectly increase creativity (Hypothesis 2).

\section{Method}

\subsection{Participants}

One hundred-forty-six individuals ( 77 women, 68 men, 1 unspecified; $M_{\text {age }}=21.33$ years, $S D=2.77$ ) with no colour vision deficiency participated in the study for a small gift. The target sample size was calculated using an estimated effect size, $f$, of 0.33 , the average value of previously reported effect sizes for the colour-approach motivation link (Elliot et al. 2007; Mehta and Zhu 2009; Rook 2014). This would require a sample size of 147 participants for the study to be powered at $95 \%$. Participants were randomly assigned to the blue $(\mathrm{N}=46)$, red $(\mathrm{N}=49)$, and control $(\mathrm{N}=51)$ conditions.

\subsection{Procedure}

The experimental room at [location masked for blind review] was $9.7 \times 4.6 \times 2.9$ metres in size. The walls and the ceiling were white and the linoleum-covered floor was dark grey. The windows were blinded in order to prevent the influence of natural light during the experiment. The room was furnished with four lines of desks and chairs as a regular lecture room. Functional white lighting was provided 
by neutral white fluorescent lamps $\left(\mathrm{R}_{\mathrm{a}}=85\right)$ and was held constant in all conditions (see Table 1). Blue, red, and white (control) accent lighting was provided using a $50 \mathrm{~W}$ LED-based wall washer (see supplementary material for pictures). The distance between the ceiling lamps and the accent-lighted wall was 1.2 metres in order to avoid reflections and provide the required light distribution for reading and writing. Thus, illuminance level, colour temperature, and chromaticity on the workstation did not differ in the three conditions.

Participants (up to eight at once) were asked to take a seat at the desk, in a position facing the wall on which the accent coloured light was projected (the respective lighting condition was set up prior to their arrival). Participants first answered control questions regarding their current mood on a 9-point scale $(1=$ very, $9=$ very good). Then, participants completed a task measuring their regulatory focus ${ }^{1}$ and a task assessing their approach motivation, after which their creative performance was measured. After the completion of the approach motivation and the creativity blocks, participants rated the difficulty of the tasks, how motivated they were, how much fun it was completing the tasks $(1=$ not at all, $9=$ very much), and reported their current mood. All tasks were completed by paper and pencil. Finally, participants indicated their age and sex, after which they were debriefed and thanked. The overall experimental session lasted 15 minutes.

\subsection{Measures}

Building on regulatory focus research (Higgins 1997), approach and avoidance motivation were measured strategic means via a "connecting-the-dots" task (Förster, Higgins, and Bianco 2003). This task requires participants to draw pictures by connecting numbered dots within a given time. Participants were informed to connect the numbered dots in each of the four presented pictures as quickly and as thoroughly as possible. The time limit per picture was 30 seconds and this was 
monitored with a stopwatch by the experimenter. The number of dots that participants connected in each picture was summed up and indicated their speed. High speed reflects eagerness, a typical approach strategy. The number of dots that participants missed (e.g., that were not connected or wrongly connected) was summed up across the three pictures and divided by the number of connected dots. High accuracy reflects vigilance, a typical avoidance strategy.

Creativity was assessed with two standard tests of creative generation: the "unusual uses" task (Guilford 1967) and the structured imagination task (Ward 1994). In the unusual uses task, participants were given two minutes to generate as many alternative uses for an empty beverage can as they could. In the structured imagination task, participants were instructed to imagine traveling to another planet anywhere in the universe and to spend 3 minutes drawing a picture of an alien creature that is local to this planet on a blank sheet of paper. Three independent coders who were blind to the conditions coded participants' alternative uses of the beverage cans in terms of creativity (on a scale of 1 (= not creative at all) to 9 (= extremely creative; Friedman et al. 2003) and the originality of the drawings from the structured imagination task on a scale of 1 (= not at all) to 5 (= very strongly; see also Maddux and Galinsky 2009). The inter-rater reliability was very good for the alternative uses ratings (ICC $(2,3)=.93$; Landers 2015) and reached an acceptable degree for ratings of the drawings $(\operatorname{ICC}(2,3)=.88)$ and were hence averaged in both cases. Measures of creative performance were the number of creative answers (with ratings above 5) in the alternative uses task and the average originality rating for the structured imagination task. To obtain one measure of creative performance from both tests, the creativity scores were z-standardized and averaged.

\section{Results}


Lighting condition significantly affected speed in the connecting-the-dots task ( $F$ $(2,143)=4.21, p=.01)$, but not accuracy $(F(2,143)=.08, p=.92)$. Planned contrasts (white, $\lambda=-2$; red, $\lambda=1$; blue, $\lambda=1$ ) showed that participants in the white light condition were slower (connected fewer dots) than participants in the blue ( $t$ $(95)=2.64, p=.01, d=.52,95 \% C I[0.11,0.92])$ and $\operatorname{red}(t(98)=2.43, p=.01, d$ $=.48,95 \% C I[0.10,0.88])$ conditions. To test our second hypothesis, we conducted OLS mediation analyses using a bias-corrected bootstrapping procedure with 10,000 bootstraps (Hayes, 2015). As we have three different lighting conditions, we conducted the analysis with a multicategorical independent variable, where $\mathrm{k}-1$ variables $(\mathrm{D} 1=$ red, D2 = blue $)$ are automatically constructed and the group with the smallest numerical code (here the control condition, white) is treated as the reference category (Hayes 2015; Hayes and Preacher 2014). The results revealed that approach strategy (speed) was positively related to creativity $(r=.20$, $p=.01)$ in correlation (see Table 2$)$ and regression analyses $(b=.02, p=.006)$. Results also supported the hypothesized mediational model. Specifically, the indirect effects of red (indirect effect $=.09, S E=.06,95 \% C I[.01 ; .24])$ and blue (indirect effect $=.09, S E=.05,95 \% C I[.02 ; .23]$ ) on creativity via approach strategy were positive and the confidence intervals did not include zero $^{2}$. The effects of lighting on task difficulty, task motivation, fun, and mood were not significant $(p>.10)$.

\section{Discussion}

As creativity influences individual performance and can foster organizational productivity (Sternberg 1999), the investigation of the impact of physical environment on creativity is of high relevance. Combining previous findings on creativity-supportive colour and light settings (e.g., Elliot and Maier 2012; Ceylan, Dul, and Aytac 2008; Mehta and Zhu 2009), we aimed to clarify how coloured 
accent light affects creativity. The results show that coloured accent lighting triggers approach motivation, which indirectly improves creative performance. In particular, participants sitting in front of walls accented by blue or red light were faster at a connecting-the-dots task than participants sitting in front of a wall accented by white light. This heightened speed can be interpreted as a strategy of eagerness typical for approach motivation. Moreover, the blue and red coloured accent light promoted creative performance via approach motivation. No differences were found regarding accuracy, an avoidance strategy, and the regulatory orientation towards approach or avoidance goals. Together, this indicates that, compared to white accent light, blue and red accent lighting elicits stronger approach behaviour and in turn improves performance in creativity tasks.

Present findings contribute to the understanding of coloured lighting's effects on creativity and provide techniques for optimising individual's performance. First, the current research suggests that the effect of coloured objects cannot be directly transferred to coloured light. Thus, colour research showed that blue and red contextual cues activate different semantic concepts like freedom and danger, which facilitate or hinder creative processing (Elliot and Maier 2012). In contrast to these findings, the present study showed that red accent light had similar effects as blue accent light leading to higher approach motivation and creativity than white accent light. Apparently, being employed in coloured accent lighting provided the colour red with positive meaning, presumably due to cosiness and relaxation cues, instead of sending a danger signal. This is in line with previous research indicating that both blue and red coloured accent light (Kuijsters et al. 2015) and walls (Dijkstra, Pieterse, and Pruyn, 2008; Küller, Mikellides, and Janssens 2009) may evoke pleasant feelings. Thus, the present findings contribute to the research on the colour-in-context theory (Elliot and Maier 2012) by emphasizing the importance of 
room appearance due to coloured accent light. Overall, this highlights the importance of considering the contextualized meanings and messages associated with specific colours in order to predict the consequences for motivation and creative performance.

Second, the current research demonstrates the underlying process in the link coloured accent light and creativity explaining why light can foster creative performance. Previous research indicated that approach motivation evoked by specific meanings of colours is positively related to creativity (Elliot and Maier 2012; Mehta and Zhu 2009; Rook 2014). Similarly, lighting research showed that dim light yields a feeling of being free from constraints and promoting creativitysupportive explorative processing style (Steidle and Werth 2013). Thus, connecting colour and lighting research, we demonstrated that coloured accent light promotes approach motivation and leads to creativity. This is important, as approach motivation is related to many other psychological processes and performance outcomes that are relevant in organisational context. For instance, approach motivation has been shown to be related to positive affect (Elliot and Thrash 2002) and global processing style (Gasper and Clore 2002), and to impact cooperation in economic decision tasks (Harlé and Sanfey 2010). Hence, approach motivation induced by coloured accent light could also have impact on other performance outcomes.

Third, the present research is also one of the few works bridging the gap between colour and lighting research. The majority of research of visual environmental features merely focuses on coloured objects (e.g., Kwallek et al. 1997; Lichtenfeld et al. 2012) or on brightness (Steidle and Werth, 2013), while only a few studies from the area of lighting research directly manipulated the coloured light (e.g., Hoonhout et al. 2009; Kuijsters et al. 2015). To our knowledge, 
the present study was the first one to test the effect of coloured accent light on the approach motivation as an underlying process leading to higher creative performance. Moreover, in this work, we also introduced and explored an economically efficient and simple method to manipulate the coloured light by using a wall washer.

As expected, we found no effects of coloured light on task difficulty, task motivation, and mood in the present study. In lighting research, a series of studies by Steidle and Werth (2013) showed that using task difficulty, task motivation, and mood as covariates does not change the lighting's effect on creativity. These effects support our results, as both colours and light are visual attributes that may shape creativity-supportive room atmosphere. Moreover, the research on effects of light and colours on mood is inconclusive (e.g., Küller et al. 2006; Knez 1995; Knez and Enmarker 1998; Lichtenfeld et al. 2012; Steidle and Werth 2013). One recent study (Plitnick et al., 2010) showed that exposure to red and blue light increases momentary mood. However, in Plitnick et al.'s study, participants were exposed to the red or blue light for sixty minutes and the authors reported changes in objective measures (EEG recordings). Possibly, shorter coloured light exposure is not able to provide physical and consequently self-reported changes in mood. Moreover, in the present study, participants worked on tasks under white light, whereas participant in Plitnick et al.'s study were directly exposed to coloured light. Thus, further research is needed to investigate whether longer exposure to coloured light promotes creativity due to changed mood.

The results of this experiment should be interpreted in light of their limitations. Despite the promising finding of the positive value of coloured light, it is far too early to generalize the findings or generally recommend using coloured light to enhance creativity. Future research is needed to investigate whether other 
forms of coloured lighting like accent lighting directed at another part of the room (e.g., the ceiling) or coloured general illumination (e.g., only blue or red light) could lead to similar results. Moreover, there may very well be situations in which perceiving no colours (i.e., only black-white) may be more beneficial for creativity because black-white perception can promote a creativity-supportive abstract information processing style (Lee et al. 2014). Furthermore, the participants of our study were students. As tasks of different occupational groups have lower or higher task complexity, it would also be interesting to investigate whether the effects of coloured light on creativity depends on task difficulty. Thus, the effects of coloured accent light - on psychological functioning in general and creativity in particular — deserve further exploration.

Despite these limitations, the present research provides practical implications for the design of workplaces in organizations, universities, and schools for creative work. Employers should think about the subjective appraisals of rooms to facilitate or optimize the performance of employees. More concrete, it is important to consider how coloured light is perceived and which atmosphere and feelings it evokes. Thus, employing coloured accent light can contribute to a pleasant, lively and cosy ambience, trigger concomitant approach motivation, and in turn enhance creativity. Transferring this knowledge into practice, a number of possibilities can be thought of in order to facilitate creativity by using coloured accent light. Focusing on non-permanent solutions within a given work context, potential applications comprise employing wall washer that can be used while working creative or creating suitably accent coloured environments for such work activities. However, whether employees would accept such coloured lighting in the first place is undetermined. Coloured lighting is, as yet, mostly used in art or design but not in the working context (Agoston 2013; Verganti 2006). 


\section{Conclusion}

The present experimental study demonstrated that blue and red accent light promotes approach motivation and in turn facilitates creativity. Although future research is still needed to further validate these findings, the present results implicate interesting possibilities for the design work places for creative activities. 


\section{Footnotes}

${ }^{1}$ Lighting condition did not affect participant's regulatory focus and regulatory focus was not related to creative performance.

${ }^{2}$ To test for potential biases, we repeated the analyses and separately included age and gender as covariates. The effect of coloured light on approach motivation and the indirect effect on creativity after controlling for these variables (all $p s<.05$, CIs did not include zero) remained significant. There were no interaction effects between lighting condition and sex, as well as between lighting condition and age (all $p \mathrm{~s}>.05$ ). Hence, the reported effects cannot be attributed to differences in age and sex. Analyses can be obtained from the first author. 


\section{References}

Agoston, G. A. 2013. Color theory and its application in art and design. Springer. Berlin.

Amabile, T. M. 1996. Assessing the work environment for creativity. Academy of Management Journal, 39: 1154-1184. doi:10.2307/256995

Amabile, T. M. 1983. The social psychology of creativity. New York: Springer.

Arnold, M. 1960. Emotion and personality. NY: Columbia University Press.

Baas, M., De Dreu, C. K., and B. A. Nijstad. 2008. A meta-analysis of 25 years of mood-creativity research: Hedonic tone, activation, or regulatory focus? Psychological Bulletin 134: 779-806. doi:10.1037/a0012815

Boyce, P. R. 2014. Human factors in lighting. Crc Press. London. New York.

Ceylan, C., Dul, J., and S. Aytac. 2008. Can the office environment stimulate a manager's creativity? Human Factors and Ergonomics in Manufacturing \& Service Industry 18: 589-602. doi:10.1002/hfm.20128

Derryberry, D., and D. M. Tucker. 1994. Motivating the focus of attention. In P. M. Niedenthal \& S. Kitayama (Eds.), The heart's eye: Emotional influences in perception and attention (pp. 167-196). San Diego, CA: Academic Press.

Dijkstra, K., Pieterse, M. E., \& A. T. H. Pruyn. 2008. Individual differences in reactions towards color in simulated healthcare environments: The role of stimulus screening ability. Journal of Environmental Psychology 28: 268277. doi:10.1016/j.jenvp.2008.02.007 
Dul, J., and C. Ceylan. 2011. Work environments for employee creativity. Ergonomics 54: 12-20. doi:10.1080/00140139.2010.542833

Elliot, A.E. 2015. Color and psychological functioning: a review of theoretical and empirical work. Frontiers in Psychology 6: 368-376. doi:10.3389/fpsyg.2015.00368

Elliot, A. J. 2006. The hierarchical model of approach-avoidance motivation. Motivation and Emotion 30: 111-116. doi:10.1007/s11031-006-9028-7

Elliot, A. J., and M.A. Maier. 2012. Color-in-context theory. In: Plant, A., Devine, P.: Advances in Experimental Social Psychology 45: 61-125. doi:10.1016/B978-0-12-394286-9.00002-0

Elliot, A.J., Maier, M.A., Moller, A.C., Friedmann, R., and J. Meinhard 2007. Color and psychological functioning: The effect of red on performance attainment. Journal of Experimental Psychology: General 136: 154-168. $\underline{\text { doi:10.1037/0096-3445.136.1.154 }}$

Elliot, A. J., and D. Niesta. 2008. Romantic red: Red enhances men's attraction to women. Journal of Personality and Social Psychology 95: 1150-1164. $\underline{\text { doi: } 10.1037 / 0022-3514.95 .5 .1150}$

Elliot, A. J., and T. M. Thrash. 2002. Approach-avoidance motivation in personality: approach and avoidance temperaments and goals. Journal of Personality and Social Psychology 82: 804-818. doi:10.1037/0022$\underline{3514.82 .5 .804}$

EN, C. (2002). 12464-1. Light and lighting-Lighting of work places-Part 1: indoor work places.

Friedman, R. S., Fishbach, A., Förster, J., and L. Werth. 2003. Attentional priming 
effects on creativity. Creativity Research Journal 15 (2-3): 277-286.

doi:10.1080/10400419.2003.9651420

Friedman, R. S., and J. Förster. 2010. Implicit affective cues and attentional tuning: An integrative review. Psychological Bulletin 136: 875-893. $\underline{\text { doi:10.1037/a0020495 }}$

Förster, J., Higgins, E. T., and A. T. Bianco. 2003. Speed/accuracy decisions in task performance: Built-in trade-off or separate strategic concerns? Organizational Behavior and Human Decision Processes 90: 148-164. doi:10.1016/S0749-5978(02)00509-5

Gasper, K., and G. L. Clore. 2002. Attending to the big picture: Mood and global versus local processing of visual information. Psychological Science 13: 34-40. doi:10.1111/1467-9280.00406

Guilford, J. P. 1967. The nature of human intelligence. New York, NY: McGrawHill.

Harlé, K. M., and A. G. Sanfey 2010. Effects of approach and withdrawal motivation on interactive economic decisions. Cognition and Emotion 24: 1456-1465. doi:10.1080/02699930903510220

Hayes, A. F., and K. J. Preacher. 2014. Statistical mediation analysis with a multicategorical independent variable. British Journal of Mathematical and Statistical Psychology 67: 451-470. doi:10.1111/bmsp.12028

Hayes, A. F. 2015. An index and test of linear moderated mediation. Multivariate Behavioral Research 50: 1-22. doi:10.1080/00273171.2014.962683

Higgins, E.T. 1997. Beyond pleasure and pain. American Psychologist 52 (12): 1280-1300. doi:10.1037/0003-066X.52.12.1280 
Hoonhout, H.C.M., Knoop, M., and R. Vanpol. 2009. Colored lighting in offices the new caffeine? Looking into performance effects of colored lighting. Proceedings of the Human Factors and Ergonomics, Society Annual Meeting 2009 53: 502-506. doi:10.1177/154193120905300804.

Kaya, N. and H. H. Epps. 2004. Relationship between color and emotion: a study of college students. College Student Journal 38: 396-405.

Knez, I. 2001. Effects of colour of light on nonvisual psychological processes. Journal of Environmental Psychology 21: 201-208. doi:10.1006/jevp.2000.0198

Knez, I., and I. Enmarker. 1998. Effects of office lighting on mood and cognitive performance and a gender effect in work-related judgment. Environment and Behavior 30: 553-567. doi:10.1177/001391659803000408

Kuijsters, A., Redi, J., de Ruyter, B., and I. Heynderickx. 2015. Lighting to make you feel better: Improving the mood of elderly people with affective ambiences. PloS ONE 10(7): e0132732. doi:10.1371/journal.pone.0132732

Küller, R., Ballal, S., Laike, T., Mikellides, B., and G. Tonello. 2006. The impact of light and colour on psychological mood: a cross-cultural study of indoor work environments. Ergonomics 49: 1496-1507. doi:10.1080/00140130600858142

Küller, R., Mikellides, B., and J. Janssens. 2009. Color, arousal, and performance a comparison of three experiments. Color Research and Application 34: 141-152. doi:10.1002/col.20476

Kwallek, N., Woodson, H., Lewis, C.M., and C. Sales. 1997. Impact of three interior color schemes on worker mood and performance relative to 
individual environmental sensitivity. Color Research and Application 22:

121-132. doi:10.1002/(SICI)1520-6378(199704)22:2<121::AID-

\section{COL7>3.0.CO;2-V}

Landers, R.N. 2015. Computing intraclass correlations (ICC) as estimates of interrater reliability in SPSS. The Winnower 2: e143518.81744. doi:10.15200/winn.143518.81744

Lee, H., Deng, X., Unnava, H.R., and K. Fujita. 2014. Monochrome forests and colourful trees. The effect of black-and-white versus color imagery on construal level. Journal of Consumer Research 41: 1015-1032. doi:10.1086/678392

Lichtenfeld, S., Elliot, A.J., Maier, M.A. and R. Pekrun. 2012. Fertile green: green facilitates creative performance. Personality and Social Psychology Bulletin 38: 1-14. doi:10.1177/0146167212436611

Maddux, W. W., and A. D. Galinsky. 2009. Cultural borders and mental barriers: The relationship between living abroad and creativity. Journal of Personality and Social Psychology 96: 1047-1061. doi:10.1037/a0014861

Maier, M.A., Elliot, A.J., and S. Lichtenfeld. 2008. Mediation of the negative effect of red on intellectual performance. Personality and Social Psychology Bulletin 34: 1530-1540. doi:10.1177/0146167208323104

Martindale, C. (1995). Creativity and connectionism. In S. M. Smith, T. B. Ward, \& R. A. Finke (Eds.), The creative cognition approach (pp. 249-268). Cambridge, MA: Bradford 
McCrae, R. R. 1987. Creativity, divergent thinking, and openness to experience. Journal of personality and social psychology, 52: 1258-1265. doi:10.1037/0022-3514.52.6.1258

Mednick, S. A. 1962. The associative basis of the creative process. Psychological Review, 69: 220-232. doi:10.1037/h0048850

Mehta, R., and R. Zhu. 2009. Blue or red? Exploring the effect of color on cognitive task performances. Science 323: 1226-1229. $\underline{\text { doi:10.1126/science. } 1169144}$

Meier, B.P., D’Agostino, P.R., Elliot, A.J., Maier, M.A., and B. M. Wilkowski. 2012. Color in context: Psychological context moderates the influence of red on approach and avoidance-motivated behavior. PLOS ONE 7(7): e40333. doi:10.1371/journal.pone.0040333

Mumford, M. D. 2003. Where have we been, where are we going? Taking stock in creativity research. Creativity Research Journal 15: 107-120. doi:10.1080/10400419.2003.9651403.

Plitnick, B., Figueiro, M. G., Wood, B., and M.S. Rea. 2010. The effects of red and blue light on alertness and mood at night. Lighting Research \& Technology 42: 449-458. doi:10.1177/1477153509360887

Rook, L. 2014. Exposure to the color red enhances creative thinking depending on appetitive-aversive cues. Creativity Research Journal 26: 124-130. doi:10.1080/10400419.2014.873672

Scott, G., Leritz, L. E. and M. D. Mumford, 2004. The effectiveness of creativity training: a quantitative review. Creativity Research Journal, 16: 361-388. doi:10.1080/10400410409534549 
Siemon, D., and S. Robra-Bissantz. 2016. Design guidelines for context-aware creativity support systems. Journal of Creativity and Business Innovation 2: $5-19$.

Smith, S. M., and S. E. Blankenship 1991. Incubation and the persistence of fixation in problem solving. The American Journal of Psychology 104: 6187. doi:10.2307/1422851

Smith, S. M., Ward, T. B., and R. A. Finke. 1995. The creative cognition approach. Cambridge, MA: MIT Press.

Steele, K.M. 2014. Failure to replicate the Mehta and Zhu (2009) color-priming effect on anagram solution times. Psychological Bulletin Review 21: 771776. doi:10.3758/s13423-013-0548-3

Steidle, A., and L. Werth. 2013. Freedom from constraints: Darkness and dim illumination promote creativity. Journal of Environmental Psychology 35: 67-80. doi:10.1016/j.jenvp.2013.05.003

Sternberg, R. J. 1999. The theory of successful intelligence. Review of General Psychology 3: 292-316. doi:10.1037/1089-2680.3.4.292

Sternberg, R. J. 1988. Mental self-government: A theory of intellectual styles and their development. Human Development 31: 197-224. doi:10.1159/000275810

Sternberg, R. J. 2006. The nature of creativity. Creativity Research Journal 18: 8798. doi:10.1207/s15326934crj1801_10

Verganti, R. 2006. Innovating through design. Harvard Business Review 84: $114-122$. 
Ward, T. B. 1994. Structured imagination: The role of category structure in exemplar generation. Cognitive Psychology 27: 1-40.

doi:10.1006/cogp.1994.1010 
Table 1

Illuminance level, Correlated Colour Temperature (CCT), and $(x, y)$ Chromaticity in Three Lighting Conditions

\begin{tabular}{|c|c|c|c|c|c|c|c|c|c|c|c|c|}
\hline & \multicolumn{4}{|c|}{ Measurements at the accent } & \multicolumn{8}{|c|}{ Measurements at the workstation $^{2}$} \\
\hline & \multicolumn{4}{|c|}{ coloured wall $^{1}$} & & & & & & & & \\
\hline & & $\mathrm{CCT}^{3}(\mathrm{~K})$ & $\mathrm{X}$ & $\mathrm{y}$ & Illuminance & (lx) & CCT $(\mathrm{K})$ & & $\mathrm{X}$ & & $\mathrm{y}$ & \\
\hline & (lx) & & & & horizontal $^{4}$ & vertical & horizontal & vertical & horizontal & vertical & horizontal & vertical \\
\hline red & 300 & $<2000$ & .491 & .330 & 640 & 200 & 3800 & 3600 & .330 & .330 & .320 & .320 \\
\hline blue & 280 & $>10000$ & .208 & .230 & 640 & 200 & 3800 & 3600 & .330 & .330 & .320 & .320 \\
\hline white & 300 & 4000 & .330 & .320 & 640 & 200 & 3800 & 3600 & .330 & .330 & .320 & .320 \\
\hline
\end{tabular}

Note. ${ }^{1}$ measurements were conducted at the coloured wall approximately $30 \mathrm{~cm}$ above the wall-washer; ${ }^{2}$ the workstation are the tables where participants worked on approach motivation and creativity tasks; ${ }^{3} \mathrm{CCT}$ was calculated using $\left(u^{\prime}, v^{\prime}\right)$ chromaticity space; illuminance level, colour temperature, and chromaticity at all workstations similar; ${ }^{4}$ In line with the current lighting standards (EN 12464), the horizontal illuminance measured on the surface of the table (workstation); the vertical illuminance measured at a height of $1.20 \mathrm{~m}$ (approximately at the height of the line of sight of a sitting person). 
Table 2

Descriptive Statistics and Correlations

\begin{tabular}{|c|c|c|c|c|c|c|c|c|c|c|c|c|c|}
\hline & \multirow{2}{*}{\multicolumn{2}{|c|}{ Variables }} & \multicolumn{2}{|c|}{ Blue } & \multicolumn{2}{|c|}{ Red } & \multicolumn{2}{|c|}{ White } & \multirow[t]{2}{*}{ Mean } & \multirow[t]{2}{*}{ SD } & \multirow[t]{2}{*}{1} & \multirow[t]{2}{*}{2} & \multirow[t]{2}{*}{3} \\
\hline & & & Mean & SD & Mean & SD & Mean & SD & & & & & \\
\hline \multirow{2}{*}{\multicolumn{2}{|c|}{ 1. Creativity }} & Task 1 & 3.42 & 2.28 & 3.51 & 2.22 & 3.97 & 1.78 & 3.64 & 2.10 & & & \\
\hline & & $\begin{array}{l}\text { Average } \\
\text { (z-value) }\end{array}$ & -0.09 & 0.97 & 0.00 & 0.82 & 0.08 & 0.70 & 0.00 & 0.83 & - & & \\
\hline 3. & Accuracy & & 10.02 & 19.34 & 9.30 & 17.29 & 8.48 & 19.67 & 9.24 & 18.68 & -.05 & -.05 & \\
\hline 4. & Regulatory & oals & 0.89 & 2.36 & 1.19 & 1.93 & 1.12 & 2.82 & 1.07 & 2.39 & -.09 & .06 & .03 \\
\hline
\end{tabular}

Note. $N=143-146$; Task $1=$ Unusual Uses Test, Task 2 = Structured Imagination Task. To facilitate the interpretation of the creativity values, raw mean values for separate creativity tasks are presented. For correlations, we used standardized values of creativity. ${ }^{*} p<.05$. 